\title{
Effect of Company during Academic Years on Habit of Cigarette Smoking among Doctors
}

\author{
Awais Mustafa, ${ }^{1}$ Humaira Zafar, ${ }^{2}$ Shahbano Jawad, ${ }^{3}$ Roman Akram ${ }^{4}$
}

\section{Abstract}

Objective: To assess the effect of company during academic years on the habit of cigarette smoking.

Materials and Methods: This Cross-sectional descriptive study was conducted in 130 doctors from three different hospitals of Lahore. Written consent was taken; participants were questioned about smoking habit. Data was analyzed using SPSS20.

Result: Doctors (all smokers) were questioned about smoking habits. Response rate was $100 \%$. The greatest percentage of Doctors started smoking due to influence of friends and family (65\%). Majority of them stayed in private hostels (58\%) and flats (29\%) during their academic years. These doctors showed greater tendency towards smoking than the doctors that stayed with their family/children (15\%).

Conclusion: Our results showed a marked tendency of tobacco smoking in doctors living without their families/children in Lahore. Majorities have the smokers in their friend's circle and had started smoking under influence of them. Doctors who lived in private

\footnotetext{
${ }^{1}$ House Officer, Services Hospital, Lahore

${ }^{2}$ Medical Officer, Services Hospital, Lahore

${ }^{3}$ House Officer, Services Hospital, Lahore

${ }^{4}$ Demonstrator, Azrah Naheed Medical College, Lahore
}

Date of Submission: 03-02-2017

Date of Revision Received: 25-04-2017

Date of Acceptance for Publication: 26-06-2017

Conflict of Interest: None

Funding Source: None

\section{Contribution}

All Authors have contributed in Study Design, Data Collection, Data Analysis, Data Interpretation, Manuscript Writing and Approval. flats/hostels showed increase in tobacco use than who lived in the houses.

Key words: Cigarette smoking, Hostelites, Smokers in friends and family.

\section{Introduction}

Tobacco smoking is the practice in which tobacco is burnt and resulting smoke is inhaled. There are many routes through which resulting smoke is inhaled (cigarette, cigars, sheesha) this exercise had its roots in ancient times (5000-3000 BC). ${ }^{1}$

Tobacco outbreak had killed 100 million people globally in $20^{\text {th }}$ century. During $21^{\text {st }}$ century it could execute one billion. It has shattered more people than HIV/Aids and Malaria and by 2030 the death index will cross 8 million a year (WHO report on global epidemic 2008). ${ }^{2}$

Pakistan is the largest customer of tobacco in south Asia regardless of the fact that it is strictly prohibited in public areas. According to various researches, tobacco smoking is very common among teenagers and is responsible for various health problems in youngsters. $^{3}$

Doctors and paramedic staff are on the front foot of health care system. Research has shown that medical intellectuals can be effective in helping patient to quit smoking.

According to large scale analysis medical scholars can be more productive in helping patients to quit smoking. ${ }^{4}$

As they are in reach of high percentage of the population, they can educate people regarding smoking cessation and demand reduction measures from higher authorities in the form of campaigns and seminars. ${ }^{5}$

Physicians are immense source of inspiration for the community, their patients and companions. Unde- 
niably, doctor's office and hospital should be a representation of no smoking behavior. ${ }^{6}$

In the developed countries like US the earliest large scale epidemiological research revealed that around $40 \%$ physician were smoker in 1959 . Statistics decreased to $21 \%$ by mid 1970 s, and around $17 \%$ (cigarette) and $8 \%$ (cigars) by the mid- $1980 .^{7}$

Different researches are done in various centers of Pakistan to assess the smoking habits of the doctors. According to the research done in Mayo hospital in Lahore. $87 \%$ doctors are smoker. ${ }^{8}$

According to various international researches smoking and drug addiction is more common among people living in hostels. ${ }^{9}$ In a campus Hostel one meets different types of people. Some have good habits and others do not. Many doctors get indulged in wrong habits. They tend to become careless. The newly found freedom sometimes can leave them off target. They forget the aim of their life. There is a gap of research in this regard among doctors who are living in hostels. To devise a comprehensive plan for hostels authorities and government, it is the need of the hour to find out what percentage of smoking doctors actually live in hostels in their academic years.

\section{Materials and Methods}

Study Design: Cross-sectional descriptive study.

Study Area: Services hospital Lahore. Mayo Hospital Lahore, Jinnah Hospital Lahore.

Study Duration: 1 month.

Study subjects senior registrar, Post graduate trainees and house officers (all smokers).

Inclusion criteria: Doctors willing to participate falling on above criteria.

Exclusion Criteria: Doctors of other hospitals and Non-smokers.

Ethical Clearance: All the subjects were explained the purpose and process of the study. They were explained the benefits of study. Assurance was given to protect the privacy and dignity of the human study subjects.

\section{Data Collection Methods}

Questionnaire was developed in accordance with the study objectives and questions were directed to assess the main influence of starting smoking and residence during academic years. Written informed consent of all participants was taken.

\section{Sampling}

Size: Sample was calculated as '130' (all smoker doctors) using EPI info 2000 (version 1.1) with confidence level of $95 \%$.

Technique: Simple Random.

\section{Data Management and Analysis Plan}

SPSS computer software was used for entry, compilation and analysis of data. Descriptive statistics were applied on date. Frequency distribution tables and pie charts are taken from it.

\section{Results}

A total of 130 smoker doctors were selected through simple random technique. They were asked 10 questions about smoking habit to assess their psychosocial determinants.

It was found that main influences for starting smoking for those smokers' doctors were friends $(65 \%)$ and family members (12\%). Remaining $23 \%$ was due to hectic jobs, to impress the girls and family related problems (Figure 1).

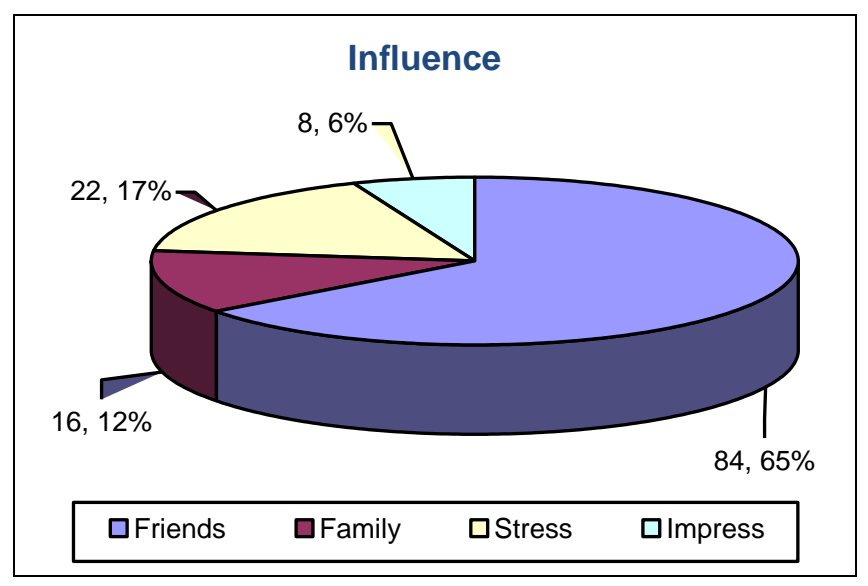

Figure 1: Main influence of Starting Smoking.

The majority of the doctors stayed in hostels $(58 \%)$ and flats (29\%). Only $13 \%$ of doctors stayed in the houses, which showed increased trend of tobacco smoking among those doctors who are away from their houses (Figure 2).

Those doctors who were living with their family/ children showed decrease trend of cigarette smoking 
(15\%). This represent their concern regarding their family and children (Figure 3 ).

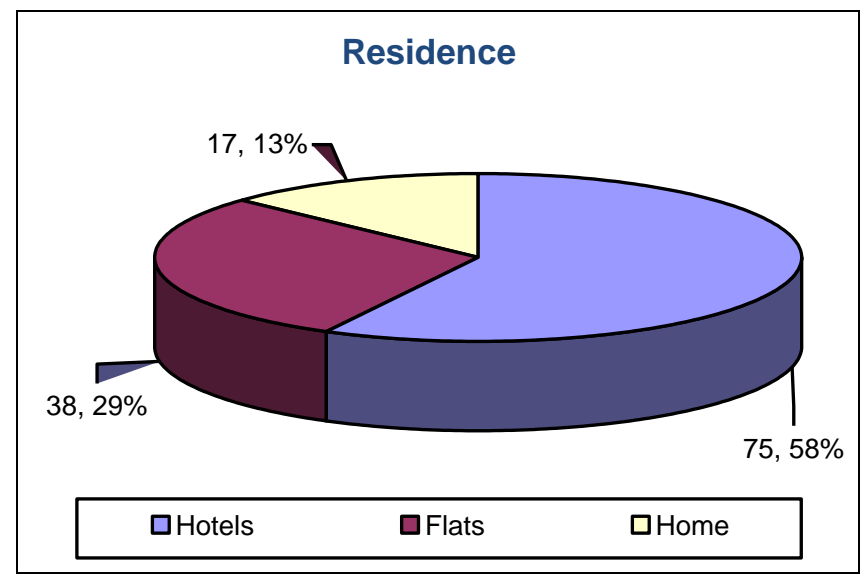

Figure 2: Residence.

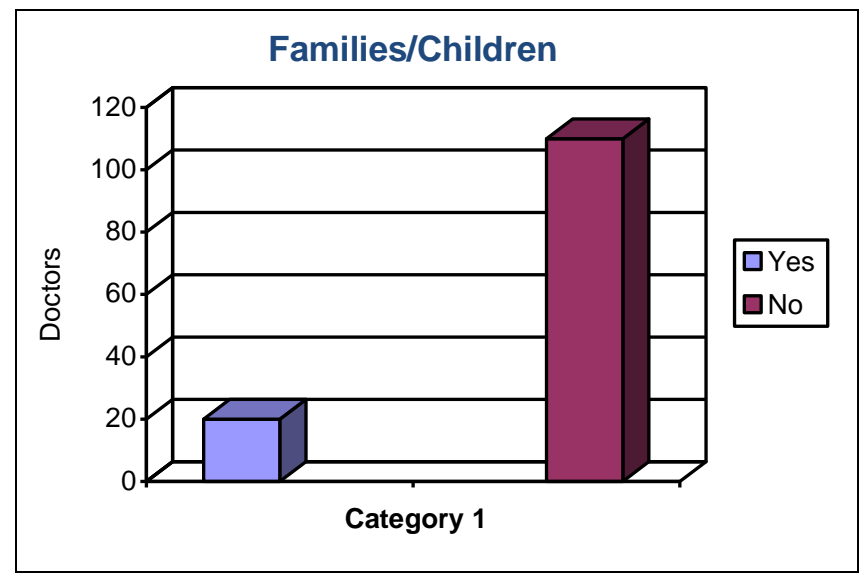

Figure 3: Family/Children.

\section{Discussion}

Doctors are an important pillar of society. They play, major role in providing health care facilities and prevention of diseases. This study was conducted to access the role of companionship on the habit of cigarette smoking among doctors.

The key finding was that $58 \%$ of doctors who smoke were living in hostels. This finding is very alarming as hostels seem to be the key place from where they acquired the habit of smoking. It is important to note that many of them started smoking during their first academic year.

Similarly, other studies reported that $30 \%$ of medical students begin smoking during their medical school years. ${ }^{10,11}$ On the contrary no medical students begin smoking after starting medical school in Philadelphia, USA. ${ }^{12}$

However, it is disturbing that $65 \%$ of doctors begin to smoke due to their friends. Which is very alarming. $17 \%$ of doctors used it to relieve stress. Smoking relieves stress and it is proven medically but effect is temporary. With the passage of time they become addicted and it gives more harm than benefit. ${ }^{13}$

Another important aspect shown in studies is $85 \%$ of doctors who smoke are not married. Among smokers only $15 \%$ were married and had children. It highlighted the point that family life and care for children play an important rule to restrain oneself away from these habits as they are passive smokers and are exposed to same amount of hazardous chemical. Research has proven that there is increase incidents of asthma and many other diseases in children of parents who smoke tobacco. ${ }^{14}$

It is interesting to know that every doctor knows that smoking is injurious to the health and they acknowledge that hostel and private flats are major places from where they get these habits.

It is a matter of debate for the administrative authorities that this very thing is happening under their eyes. They should take strict actions and arrange counselling seminars for the doctors who smoke despite of knowing that it is injurious to health. Government should direct their efforts in making smoke free zones in the public places. A study conducted in UK showed that introduction of smoke free sings maybe an effective strategy in reducing smoking around entrances and exits of public hospital

\section{Conclusion}

There is a considerable practice of cigarette smoking in health care providers (doctors, paramedical staff) working in hospitals especially those who live in hostels and private flats. We have to destroy the roots from where these habits begin and then effect with so much force that highly educated people are unable to resist them.

If healers themselves smoke, how much can they help in curing the diseases resulting from tobacco smoke? It is crucial to create realization both in health care provider and general public regarding threats of smoking and use of tobacco products as well as use of present-day expertise for quitting smoking to constraint the metastasis of this havoc. 


\section{References}

1. Gately I, Grove C. Tobacco: A Cultural History of How an Exotic Plant Seduced Civilization. New York: Diane; 2016. p.3-7.

2. World Health Organization. Report on the Global Tobacco Epidemic. Geneva: World Health Organization; 2008. Available from:

www.who.int/tobacco/mpower/mpower_report_six_pol icies_2008.pdf

3. Burki SJ, Pasha AG, Pasha HA, John R, Jha P, Baloch AA, et al. The Economics of Tobacco and Tobacco Taxation in Pakistan. Paris: Int J Tuberc Lung Dis. 2013; 15(3):1-49

4. Kass NE. An Ethics Framework for Public Health. Am J Pub Health. 2001; 91(11):1776-82.

5. WHO. Tobacco Free Initiative (TFI). 2017. (Cited 2017). Available at: www.who.int/tobacco/.

6. Nett LM. The physician's role in smoking cessation. A present and future agenda. Chest. 1990; 97(2):28S-32S.

7. Sterling TD, Weinkam JJ. Smoking characteristics by type of employment J Occup Med. 1976; 18(11):74354.
8. Malik AK, Chaudhry A, Karamat A, Arif N, Cheema MA, Rauf A. Cigarette smoking and health care professionals at Mayo Hospital, Lahore, Pakistan. J Pak Med Assoc. 2010; 60(6):509-12.

9. Abdullah AS, Qiming F, Pun V, Stillman FA, Samet JM. A review of tobacco smoking and smoking cessation practices among physicians in China: 1987 - 2010. Tob Control. 2013; 22(1):9-14.

10. Mas A, Nerín I, Barrueco M, Cordero J, Guillén D, Jiménez-Ruiz C, et al. [Smoking habits among sixthyear medical students in Spain].Arch Bronconeumol. 2004; 40(9):403-8.

11. Mubeen SM, Morrow M, Barraclough S. Smoking among future doctors in a "no-smoking" university campus in Karachi, Pakistan: issues of tobacco control. J Pak Med Assoc. 2008; 58 (5): 248-53.

12. Patkar AA, Hill K, Batra V, Vergare MJ, Leone FT. A comparison of smoking habits among medical and nursing students. Chest. 2003; 124(4):1415-20.

13. Parrott AC. Does cigarette smoking cause stress? Am Psychol. 1999; 54(10):817-20.

14. Samet J.Health Effects of Passive Smoking. In: J Frija; P Attal. Thorax. Paris: Masson. 1999; 357-66. 